\title{
The contribution of primary health care to global health
}

In March 2010, UN-Secretary General Ban $\mathrm{Ki}$-moon challenged member states to increase their efforts to achieve the Millennium Development Goals (MDGs): 'the lack of commitment increases the likelihood of a failure'. ${ }^{1}$ Nevertheless, there are positive signs: when it comes to eradication of extreme poverty, important progress has been made. Access to basic education, equity between men and women at the level of basic and secondary education, and access to water, show clear improvements. However, the picture is not that hopeful in relation to the health-related MDGs which include: reduction of child mortality and maternal mortality, tackling the HIV/AIDS problem, and preventing malaria and other diseases. ${ }^{2}$ Almost 8 million children yearly do not reach the age of 5 years and these problems are concentrated in Africa and South Asia. ${ }^{3}$ Progress is possible, as demonstrated by the countries in Latin America, where child mortality decreased between 1990 and 2008. The goal to reduce maternal mortality by $75 \%$ between 1990 and 2015 , is likely to be achieved in only 23 countries, with Sub-Saharan Africa remaining the biggest problem. ${ }^{4}$ New health problems arise in developing countries: the noncommunicable diseases (such as diabetes and heart failure) are increasing and may seriously hamper the realisation of the MDGs. ${ }^{5}$

\section{SOCIAL DETERMINANTS OF HEALTH}

It is obvious that achieving the MDGs will be closely related to the reduction of the socioeconomic inequities in health between continents and countries, and within countries. The report Closing the gap in a generation: health equity through action on the social determinants of health, by the Commission on Social Determinants of Health stresses the importance of the development of primary care in addressing socioeconomic inequities in health. ${ }^{6}$ The Commission states clearly:

\begin{abstract}
'Healthcare systems have better health outcomes when built on primary health care $(\mathrm{PHC})$ - that is, both the PHCmodel that emphasises locally appropriate action across the range of social determinants, where prevention and promotion are in balance with investment in curative interventions, and an emphasis on the primary level of care with adequate referral to higher levels of care.'
\end{abstract}

\section{THE ROLE OF FAMILY MEDICINE}

When primary health care integrates public health approaches, for example through Community Oriented Primary Care (COPC), it may contribute to achievement of MDGs. ${ }^{7}$

So, as GPs and family physicians, we have a role to play, provided we are willing to rethink the perspective of primary health care, marking the transformation of GPs from individual providers, looking at the individual needs of individual patients, into a medical team member focused on the needs of the community, working together with other community health workers while integrating personal and community health care. $^{8}$

By doing so, family medicine may contribute to important developments, such as the development of primary health care in Africa. ${ }^{9}$

The discipline of general practice/family medicine plays an important role in the choice between the horizontal versus vertical approach in health care. This integration between horizontal (personaland community-oriented care) and vertical (disease-oriented) care is increasingly important in developing countries. Organisations such as the World Bank, the International Monetary Fund (IMF), and the Bill and Melinda Gates Foundation, have concentrated on vertical programmes. An increasing amount of evidence demonstrates that there is a need to integrate disease-oriented programmes into local primary healthcare facilities to achieve reasonable prospects for successful disease control. ${ }^{10}$ Vertical programming not only leads to fragmentation of care, but also creates an 'internal brain drain', as healthcare providers working for donor-funded vertical programmes are often paid more than double those of equally trained government workers in the fragile public health sector. It is the underfunded primary care clinics and health centres that care for all diseases, including, common illnesses such as diarrhoea, malnutrition, and respiratory tract infections, which take many more lives than HIV, tuberculosis, and malaria. Therefore, the World Organisation of Family Doctors (Wonca), together with the Network: Towards Unity for Health, Global Health through Education, Training and Service, and the European Forum for Primary Care, have set up the ' 15 by2015' campaign to foster a better balance between vertical and horizontal aid. This campaign calls for major international donors to assign 15\% of their vertical budgets by 2015 to strengthening horizontal primary healthcare systems so that all diseases can be prevented and treated in a systematic way (www.15by2015.org).

\section{THE ROLE OF PROFESSIONAL PRIMARY CARE BODIES}

What can be the role of professional primary care bodies in global health? There are different opportunities: first of all sensitisation of membership; creating enough capacity to avoid the recruitment of physicians and nurses from developing countries in the UK. Colleges, and bodies such as the Royal College of General Practitioners (RCGP), can actively contribute to capacity building in developing countries, not by 'exporting' knowledge to the South (there is enough knowledge and wisdom present in developing countries), but by facilitating networking, in order to develop 'South-South strategies'. An opportunity here is the framework offered by 
the Primafamed network (www.primafamed.ugent.be), working with departments or units of family medicine and primary health care in Africa and Latin America. This network puts South-South cooperation into practice, as staff are, for example, circulating from one African country to another, e-learning is shared, professors of one country function as external examiners in another country. The network uses the concept of 'training complexes': these are combinations of primary healthcare centres and related clinics, with district health hospitals where family physicians and primary care nurses are trained. An example is the 'SouthAfrican family medicine twinning project' where the eight departments of family medicine of South Africa, are 'twinning' with 'training sites', even in countries where there are only the beginnings of a medical faculty, no medical faculty, or even no university (such as Botswana, Malawi, Swaziland, Lesotho, and Namibia).

\section{RESEARCH AND EDUCATION}

Another opportunity to contribute is the field of quality assurance: one of the challenges in developing countries is the increasing amount of private universities, with unclear quality of the education. In October 2010, an important conference took place in East London, South Africa, 'Towards a global consensus on medical education standards based on principles of social accountability'. This conference formulated criteria for accreditation with emphasis on social accountability education, research, and service delivery. Professional bodies such as the RCGP could contribute to the implementation of the developed criteria in education worldwide.

In the field of research, globalisation invites us to look at patient-centred care from a comprehensive perspective, as described in the World Health Report 2008: Primary health care: now more than ever. ${ }^{11}$ Research is needed to explore patient-centeredness in different socioeconomic and cultural contexts, and on human resources, for example primary health care in Africa. It was disappointing to see that the recent call of the European Union on research on human resources in health care in Africa (EU-Seventh
Framework Programme [FP7]), received only one application from a research consortium. The World Health Organization is looking for a systematic documentation of experiences to study comprehensively what is meant by people-centeredness in different contexts and to organise field visits and 'demonstration tours' to demonstrate person-centred care for staff and delegations from developing countries. Organisations such as the RCGP could contribute to these initiatives.

Development of general practice and family medicine in the framework of primary health care can only benefit from making adequate strategic choices and from focusing on increasing access (by means of universal coverage, supported by public interest, social security systems, and community-based health programmes, among others). The reorientation of the health system from hospital-centred to a focus on primary health care, and the promotion of the role of the GP/family physician within the framework of the primary healthcare team should help to limit both the internal and international brain drain.

Such a refocusing on primary health care should bring into practice the 'message of hope', as formulated by Archbishop Emeritus Desmond Tutu, in his preface to Hugo and Allen's Doctors for tomorrow: Family medicine in South Africa. ${ }^{12}$

'Doctors in family medicine are aware
of the challenges, attempt to
understand them better and work to
address them ... The issues of
principles and values, relationships
and meaning are not left to chance,
but become an important element of
service, systems, training and
research.

This gives me hope of a transformation in the health service that can take care of our people which can guide us through this difficult time. This hope is not only for South Africa, but also for our brothers and sisters in the rest of the continent and the rest of the world.

If the family medicine movement can play that role, let us join hands and realise that dream.'

\section{Jan De Maeseneer,}

Head of Department of General Practice and Primary Health Care, Ghent University, Belgium and WHO Collaborating Centre on Primary Health Care.

\section{Marc Twagirumukiza,}

Post-doctoral researcher, Department of General Practice and Primary Health Care, Ghent University, Belgium and WHO Collaborating Centre on Primary Health Care.

\section{Provenance}

Commissioned; peer reviewed.

\section{REFERENCES}

1. Ban Ki-Moon. Millennium Development Goals must be met: UN Secretary-General says ahead of September Summit.

http://www.unis.unvienna.org/unis/pressrels/2010/unisinf 357.html (accessed 10 Nov 2010).

2. Go DS, Harmler R, Turner H. Regaining momentum: progress on the Millennium Development Goals has been slowed by the crisis. Finance Dev 2010; 47(3): 6-10.

3. You D, Wordlaw T, Salama P, Jones G. Levels and trends in under-5 mortality, 1990-2008. Lancet 2010; 375: 100-103.

4. Hogan MC, Foreman KJ, Naghavi M et al. Maternal mortality for 181 countries, 1980-2008: a systematic analysis of progress towards Millennium Development Goals. Lancet 2010; 375: 1619-1632.

5. Stuckler D, Basa S, McKee M. Drivers of inequality in Millennium Development Goal progress: a statistical analysis. PLOS Medicine 2010; 7(3): e100 0241.

6. Commission on Social Determinants of Health. Closing the gap in a generation: health equity through action on the social determinants of Health. Geneva: World Health Organization, 2008.

7. Van Weel C, De Maeseneer J, Roberts R. Renewing primary health care: integration of personal and community health care. Lancet 2008; 372: 871-872.

8. De Maeseneer J, van Weel C, Roberts R. Family medicine's commitment to MDGs. Lancet 2010; 375: 1588-1589.

9. De Maeseneer J, Flinkenflögel M. Primary health care in Africa: do family physicians fit in? Br J Gen Pract 2010; 60: 286-292.

10. Unger JP, De Paepe P, Green A. A code of best practice fo disease control programmes to avoid damaging health care services in developing countries. Int $J$ Health Plann Manage 2003; 18 suppl 1: 527-529.

11. World Health Organization. Primary health care: now more than ever. Geneva: World Health Organization, 2008.

12. Hugo J, Allan L. Doctor for tomorrow. Family medicine in South Africa. Grahamstown: NISC South Africa, 2008.

DOI:10.3399/bjgp10X543998

\section{ADDRESS FOR CORRESPONDENCE}

\section{Jan De Maeseneer}

Department of General Practice and Primary Health Care, Ghent University, UZ-1K3, De Pintelaan 185, Ghent, B-9000 Belgium.

E-mail: jan.demaeseneer@ugent.be 